\title{
Three Track Teaching Mode of Sports Anatomy Based on Innovative Theory
}

\author{
https://doi.org/10.3991/ijet.v15i24.18959 \\ Yujia Ren ${ }^{(凶)}$ \\ Hunan First Normal University, Changsha, China \\ renyujia@163.com \\ Rong Tang \\ Xiangtan Medicine \& Health Vocational College, \\ Xiangtan, China \\ Xia Jiang \\ Wuhan Sports University, Wuhan, China
}

\begin{abstract}
Sports anatomy is one of the compulsory courses in college. It is an important course for undergraduate students to complete the teaching link of practicing. This course is extremely practical and operational, and requires active learning. However, due to the limited classroom time, the increase in the number of students and the shortage of anatomical specimens, the traditional teaching of anatomy fails to inspire students' interest in learning and becomes unable to adapt to the requirements of the times. In this study, a three-track teaching mode was designed on the basis of combining the innovative talent training theory with the characteristics of sports anatomy. The teaching mode in this study is composed of eight learning stages: identifying problems, analyzing problems, generating hypotheses, confirming already-known knowledge, establishing required information, confirming resources, collecting new information, combining old and new knowledge. Meanwhile, case teaching method and team-teaching method were incorporated into this mode. In addition, before, during and after class, 3D anatomy software both in the mobile version and $\mathrm{CP}$ version was used to urge students to take the initiative to learn and complete the learning tasks. Finally, according to the purpose of training innovative talents in this study, a new learning performance evaluation system was constructed in accordance with the characteristics of sports anatomy. It was found in this teaching experiment that this new teaching mode is conducive to improving the teaching effect, lays a foundation for promoting the quality of the teaching link of practicing, and stimulates the innovation ability of college students.
\end{abstract}

Keywords - Three track teaching mode; 3D animation; Sports anatomy; Innovation 


\section{Introduction}

Multimedia technology is the combination of modern teaching media and traditional teaching means, according to the characteristics of teaching and training programs and objects, to formulate the optimal theory and training plan, to achieve the best teaching effect [1]. Multimedia teaching is the product of the development and popularization of computer technology, and is the symbol of the progress from traditional teaching to modern teaching. The research points out that the ideal multimedia teaching has the following advantages: The perfect display of various art forms, the comprehensive realization of a variety of sensory stimulation, and the organic combination of various teaching means [2]. Throughout the current situation of multimedia teaching practice in Colleges and universities, the popularization rate of multimedia teaching is higher and higher, and more and more teachers use multimedia teaching. How to display the multimedia teaching perfectly in various art forms, realize the comprehensive realization of multiple sensory stimulation, and combine various teaching methods organically is a problem concerned in the field of educational technology.

Sports anatomy is the main compulsory course for students majoring in physical education in colleges and universities. It plays an important role in the curriculum system of sports majors. It can not only provide theoretical guidance for sports practice from the perspective of anatomy, but also be the basic course of a series of courses such as sports physiology and sports health science. As a future sports teacher or coach, only by mastering certain knowledge of sports anatomy can they provide more scientific and effective methods and means for sports training and health care [3]. However, the learning effect of the course is often unsatisfactory, and it is difficult to achieve the expected learning objectives. On the one hand, the teaching content of sports anatomy itself is huge and boring, and the professional terms learned are more abstract, which makes it difficult for students to have interest in learning. On the other hand, the students of physical education major have relatively weak theoretical basis, which leads to sports anatomy difficult to improve the teaching effect [4].

Therefore, based on the innovative talent training theory of college students, this study uses the three-track teaching method characterized by heuristic teaching, combines multimedia technology with network teaching platform, and carries out teaching experiments in the course of sports anatomy. At the same time, because the knowledge of anatomy is difficult to understand, a new 3D anatomy virtual technology software is introduced in this study, and the students are guided to use the software to complete the learning task in practice class. It is hoped that this teaching method can improve the teaching effect of sports anatomy through new network teaching technology and vivid teaching video resources, so as to cultivate innovative and qualified sports professionals. 


\section{State of the Art}

Multimedia technology is a hot field of computer education application, which plays an increasingly important teaching aids role in modern education. At the same time, Web3D technology, as a form of virtual reality technology, provides a broad space for the application of virtual reality technology in classroom, serving students. Three-dimensional (3D) animation technology was developed earlier in western developed countries. Due to its high authenticity, feasibility, interest and rich application advantages, it has been widely used in many fields such as medicine, education and so on. For example, Adamovillani et al. [5] applied a computer animation tool of human-computer interaction in mathematics teaching to improve the mathematical skills of deaf children. Adamovillani et al. [5] designed and established a 3D virtual signer model by using the most advanced computer animation technology, and found that the mathematical ability of deaf students can be improved by using interactive 3D animation. Korakakis et al. [6] applied 3D multimedia technology in the learning process of science students, using interactive 3D virtual environment, 3D animations interface and 3D static illustrations interface. The research results show that in the above three ways, interactive 3D virtual environment has the best learning effect. With the continuous breakthrough and gradual improvement of 3D research, some 3D anatomy software focusing on medical education, especially anatomy teaching, came into being. Hoyek et al. [7] applied three-dimensional (3D) digital animation to the teaching of human muscle and skeletal system. The team combined two-dimensional (2D) drawings with threedimensional(3D) digital animation in PowerPoint slides, and used multimedia technology to present knowledge information in anatomical specimens. The teaching results show that $2 \mathrm{D}$ drawing combined with $3 \mathrm{D}$ animation teaching technology is more conducive to improve students' interest in learning. Zhou et al. [8] discussed the application of three-dimensional technology in anatomy teaching and the production method of 3D animation. The team uses Autodesk software to 3D model the human body structure picture, uses the 3Ds MAX software to modify, render and set the light to form the three-dimensional structure or organ of the human body, and uses Unity to design the interactive operation interface, and finally presents the 3D structure on the computer or mobile phone. The results show that $3 \mathrm{D}$ digital model can improve the teaching effect and get the recognition of students.

With the rapid development of social economy, the requirements of modern society for talents are becoming more and more comprehensive and diversified. In order to cultivate talents to meet the needs of the society, the concept of school education has gradually changed and improved, that is, from the traditional mode of "taking teachers as the main body and students passively accepting knowledge" to the mode in which students can actively learn and accept knowledge. The three-track teaching mode is a teaching method of "student-centered". The three-track teaching mode combines TBL, PBL and CBL. Among them, PBL (problem-based learning) [9] refers to the problem-based learning mode, which is initiated by McMaster university to guide students to learn around the problems set by teachers; In addition, CBL (case-based learning) [10] proposed by German educators and the teaching method is to stimulate 
students' thinking ability by proposing, analyzing and discussing cases; TBL(Team based learning) teaching method proposed by Professor Michaelsen of Oklahoma university in the United States [11] refers to that through the guidance of teachers, students use team cooperation to complete relevant tasks. In short, the three-track teaching method is a combination of PBL, TBL and CBL. It is a new exploration in the teaching reform. The characteristics of this teaching method are based on constructivism and emphasize the dominant position of learners. For example, Sendag will adopt the OPBL (online problem-based learning) teaching method in the pre service teacher training course. The research collects data through open-ended questionnaire and analyzes the role perception of teachers and learners. The results show that the OPBL teaching strategy is more conducive to the acquisition of knowledge for learners. Similarly, the team-based learning method in the three-track teaching method has been continuously applied, optimized and improved in education, medicine and other fields. For example, Hrynchak et al. [12] applied (team-based learning) to health care knowledge training. Experiments have proved that this teaching method can improve learners' critical thinking ability and team cooperation ability. Wu et al. [13] applied the three-track teaching mode in pediatric teaching, focusing on team cooperation, and further applied the teaching mode to carry out pediatric practice teaching reform. The results showed that the teaching mode was an effective teaching mode conducive to cultivating innovative talents. Cai \& Zhang [14] applied the three-track teaching method in the teaching of cardiovascular internal medicine. The experimental results show that the method can greatly enhance students' interest and initiative in learning and improve their comprehensive analysis ability. Although the three-track teaching method applies and research in different courses, the teaching method has also achieved satisfactory teaching effect and student recognition, but there is no relevant research report on the application of the three-track teaching method in sports anatomy course. Sports anatomy is a basic knowledge that a sports major must learn. But the anatomy content is complex and difficult to understand, and there are many and abstract terms. Therefore, it is difficult for students to learn this course well, which puts forward higher teaching requirements for teachers. In this study, three track teaching method is first proposed to be applied in sports anatomy course. At the same time, a new 3D anatomy learning software is introduced. According to the requirements of today's society for college students' innovation ability, the evaluation index of sports majors' innovation ability is formulated on the structure of PDCA (Deming cycle), so as to dynamically evaluate the training effect of students' innovation ability. It is hoped that through the application of new technology and new means in the course of sports anatomy, a new perspective and thinking will be provided for the corresponding teaching reform. 


\section{Three Track Teaching Mode Based on 3D Animation Technology in Teaching}

\subsection{Introduction of PDCA cycle in sports anatomy teaching}

PDCA management method was a quality management system [15], which was first proposed by American scholar Hugh Hart, and then developed and applied by American statistician and quality management expert Dr. Deming. PDCA is the initials of the words Plan, Do, Check, and Action. The main characteristic of PDCA management method is that it starts from $\mathrm{P}$, goes through $\mathrm{D}$ and $\mathrm{C}$ stages, and finally starts A stage, which is continuously circulating, rising in a ladder and circulating repeatedly. The details are shown in Figure 1 below.

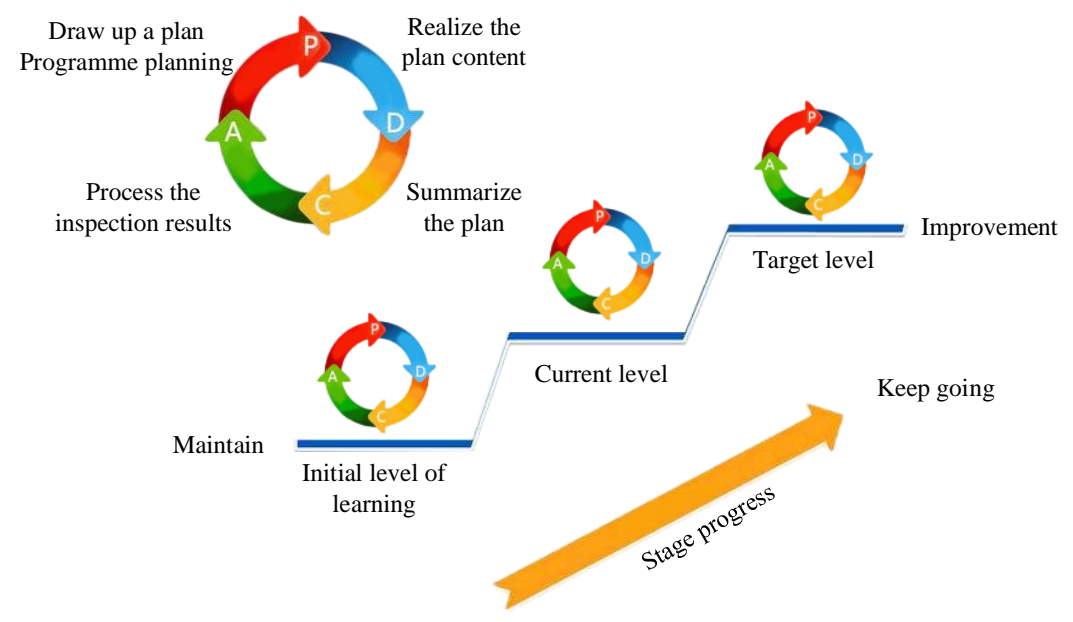

Fig. 1. PDCA cycle teaching mode

It can be seen from Figure 1 that sports anatomy is the core course of physical education. The basic task of this course is to explore and clarify the morphological characteristics and position of human organs and tissues, so as to lay a solid foundation for the study of other basic courses and clinical courses. The course has many knowledge points, complicated professional terms, and some theories and operation skills are difficult for college students to understand. How to strengthen classroom teaching management, improve students' initiative, improve students' innovation ability, actively participate in classroom teaching, let students "learn by doing, do while learning", is an important topic that needs to be studied in depth. As PDCA cycle method is the basic method of total quality management, it is also known as "Deming cycle method". The PDCA cycle is applied to classroom teaching management, corresponding to the teaching plan, teaching plan implementation, checking the implementation effect, and making the high-quality program teaching plan into the teaching standard, which needs to be improved and entered into the next 
teaching cycle as the key to solve. Therefore, the classroom teaching management can be continuously optimized and improved.

\subsection{Implementation scheme of 3D animation technology combined with three track teaching}

On the basis of previous studies, some scholars put forward eight stages of PBL learning: identifying problems; analyzing problems; generating hypotheses; confirming known; establishing required information; confirming resources; collecting new information; connecting old and new knowledge. At the same time, combined with the knowledge to explain in the form of case teaching, and the students form a team to complete the knowledge task assigned by the teacher. The specific implementation scheme is shown in Figure 2.

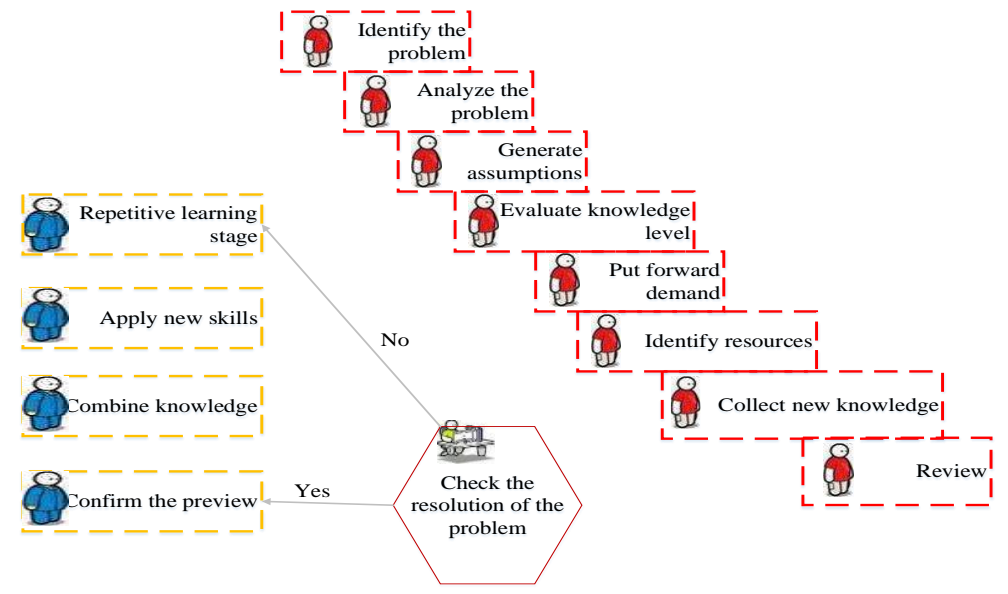

Fig. 2. Implementation scheme of three track teaching method

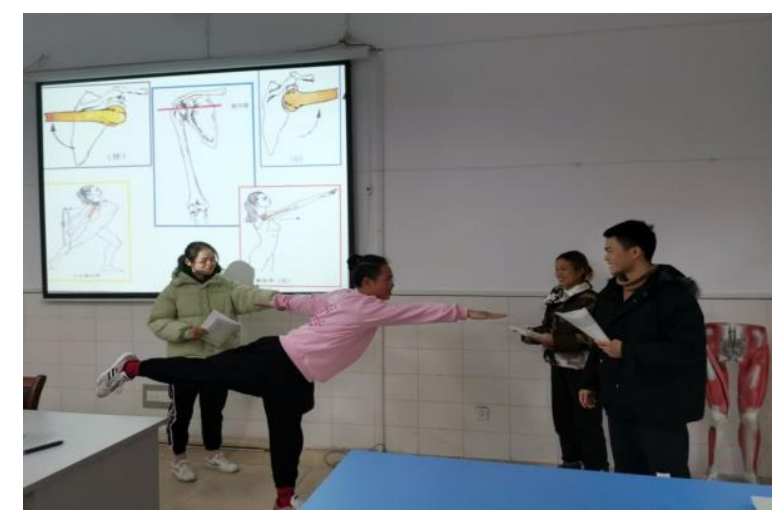

Fig. 3. Application Part 1 of three track teaching method in sports anatomy teaching 


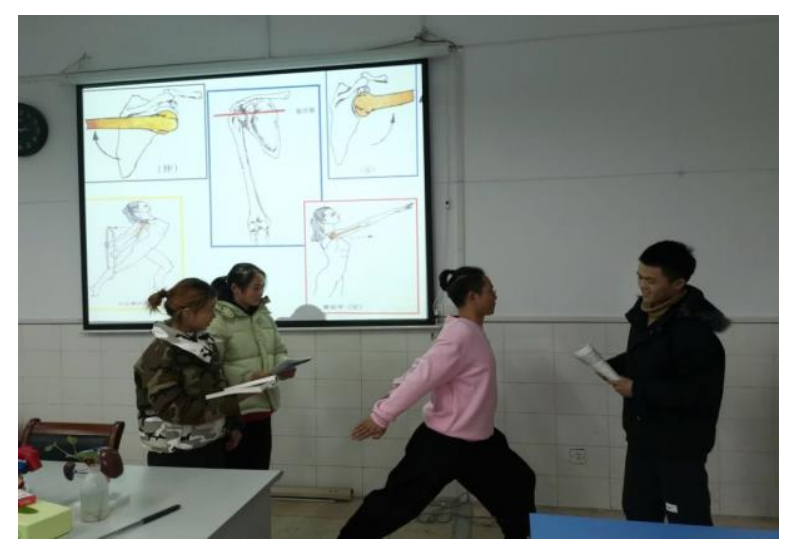

Fig. 4. Application Part 2 of three track teaching method in sports anatomy teaching

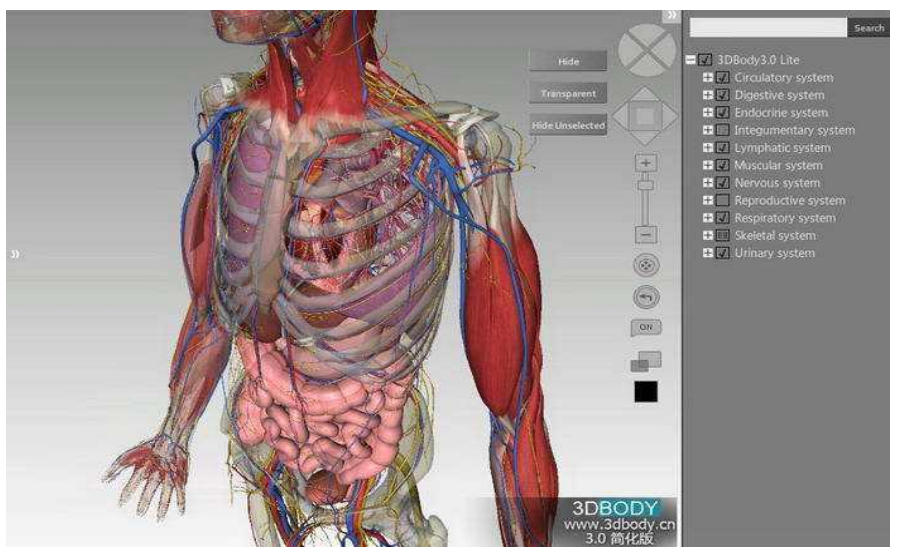

Fig. 5. Display of sports anatomy teaching design combined with 3D anatomy software

As can be seen from figure 3-4, the implementation plan of the three-track teaching method in the classroom mainly includes the following links:

1) Based on the full analysis of the curriculum system and structure, the teachers carefully design the curriculum in advance, prepare sufficient course materials such as cases, videos, and problems to be discussed, and sort out and organize the knowledge points of the course according to their own wishes

2) Before the formal opening of the class, teachers should familiarize with the class first, guide the students into groups and implement the team leader, arrange the teaching content 1-2 weeks in advance, and require students to read and digest the course content in groups

3) In the course of teaching, the students are seated in groups, and the students' mastery and application ability of professional knowledge are comprehensively cultivated through the methods of topic discussion, group display, simulation confrontation, practice design and so on 
4) After class, with the help of $3 \mathrm{D}$ sports anatomy software and multimedia teaching platform, teachers and students can communicate, answer questions, exchange experience, and adjust teaching methods and contents in time

5) The corresponding system is formulated to evaluate the learning effect of students. The students' classroom performance, group speech, question answering level, final examination and other links are quantified and included in the total classroom score according to a certain proportion.

Figure 5 shows the application of 3D anatomy software in the teaching process of sports anatomy. In this study, the free version of 3D body of mobile phone is applied. The APP is installed in the mobile phones of teachers and students. The $3 \mathrm{D}$ body is often used as a medium for discussion or review between teachers and students

\subsection{Establishing the quality evaluation system of three track teaching method based on innovation theory}

The deepening reform of innovation education is not only the urgent need of the national implementation of innovation driven development strategy, but also an important driving force to promote the rapid development of economy and society, and is also a key measure for the comprehensive reform of university campus and the strengthening of talent training in colleges and universities. Compared with the developed countries which take the lead in innovation driven development, Chinese college students generally have the problems of insufficient innovation spirit and low innovation ability in innovation and entrepreneurship. The main reason is that in the process of theoretical research and practice in colleges and universities, the interpretation of the connotation of innovation ability and the setting of training objectives are still in the initial stage, and there is no unified standard. Therefore, according to the course characteristics of sports anatomy and the application effect of the three-track teaching method, this study established a scientific, reasonable and unified evaluation index system of college students' innovation ability. The mathematical expression of factor analysis method is matrix: $X=A F+B$, namely:

$$
\left\{\begin{array}{l}
X_{1}=\alpha_{11} f_{1}+\alpha_{12} f_{2}+\alpha_{13} f_{3}+\cdots+\alpha_{1 k} f_{k}+\beta_{1} \\
X_{2}=\alpha_{21} f_{1}+\alpha_{22} f_{2}+\alpha_{23} f_{3}+\cdots+\alpha_{2 k} f_{k}+\beta_{2} \\
X_{3}=\alpha_{31} f_{1}+\alpha_{32} f_{2}+\alpha_{33} f_{3}+\cdots+\alpha_{3 k} f_{k}+\beta_{3} \\
\cdots \cdots \\
X_{p}=\alpha_{p 1} f_{1}+\alpha_{p 2} f_{2}+\alpha_{p 3} f_{3}+\cdots+\alpha_{p k} f_{k}+\beta_{p}
\end{array} \quad(k \leq p)\right.
$$

In the model, vector $\mathrm{X}(\mathrm{x} 1, \mathrm{x} 2, \mathrm{x} 3, \ldots \ldots, \mathrm{xp})$ is an observable random vector, that is, the original observation variable. $F(f 1, f 2, f 3, \ldots \ldots, f k)$ is common factors of $\mathrm{X}(\mathrm{x} 1, \mathrm{x} 2, \mathrm{x} 3, \ldots \ldots, \mathrm{xp}) . \mathrm{A}(\alpha \mathrm{ij})$ is the coefficient of common factor $\mathrm{f}(\mathrm{F} 1, \mathrm{~F} 2, \mathrm{~F} 3$, $\mathrm{FK})$, which is called the factor load matrix, $\alpha \mathrm{ij}(\mathrm{i}=1,2, \mathrm{p} ; \mathrm{J}=1,2, \ldots, \mathrm{K})$ is called factor load, which is the load of the $\mathrm{i}$-th original variable on the $\mathrm{j}$-th factor, or $\alpha$ ij can be regarded as the weight of the $\mathrm{i}$-th variable on the $\mathrm{j}$-th common factor. $\alpha \mathrm{ij}$ is the 
covariance of $x i$ and $f j$, and is also the correlation coefficient between $x i$ and $f j$, indicating the degree of dependence or correlation of $x i$ on $f j$. The larger the absolute value of $\alpha \mathrm{ij}$, the greater the load of common factor $\mathrm{f} j$ for $\mathrm{xi}$. $\mathrm{B}(\beta 1, \beta 2, \beta 3, \ldots \ldots$, $\beta p)$ is the special factor of $X(x 1, x 2, x 3, \ldots \ldots, x p)$, is the part that cannot be included by the first $\mathrm{k}$ common factors, and this factor is also unobservable. The special factors and the special factors and all the common factors are independent of each other.

The common degree of variables is the sum of squares of the elements in row $i$ of factor load matrix A. As follows:

$$
h_{i}^{2}=\sum_{j=1}^{k} \alpha_{i j}^{2} \quad(\mathrm{i}=1,2, \quad \ldots, \mathrm{p})
$$

Take the variance on both sides of Formula 1 and get the following result:

$$
\operatorname{Var}\left(x_{i}\right)=\alpha_{i 1}^{2} \operatorname{Var}\left(f_{1}\right)+\alpha_{i 2}^{2} \operatorname{Var}\left(f_{2}\right)+\cdots+\alpha_{i k}^{2} \operatorname{Var}\left(f_{k}\right)+\operatorname{Var}\left(\beta_{i}\right)=\sum_{j=1}^{k} \alpha_{i j}^{2}+\sum_{i=1}^{p} \beta_{i}^{2}
$$

If the result of $h_{i}^{2}=\sum_{j=1}^{k} \alpha_{i j}^{2}$ is close to Var (xi) and $\beta_{i}^{2}$ is very small, then the effect of factor analysis is better, and the transformation property from original variable space to common factor space is good. The sum of squares of the elements in the factor load matrix is denoted as:

$$
\mathrm{g}_{j}^{2}=\sum_{i=1}^{p} \alpha_{i j}^{2} \quad(j=1,2, \cdots, k)
$$

$\mathrm{g}_{j}^{2}$ is called variance contribution of the common factor $\mathrm{F}(\mathrm{fl}, \mathrm{f} 2, \mathrm{f} 3, \ldots \ldots, \mathrm{fk})$ to $\mathrm{X}$ $(\mathrm{x} 1, \mathrm{x} 2, \mathrm{x} 3, \ldots \ldots, \mathrm{xp})$. It represents the sum of the variances provided by the $\mathrm{j}$-th common factor $\mathrm{f} i$ for each component $\mathrm{xi}(\mathrm{i}=1,2, \mathrm{p})$ of $\mathrm{x}$, and is an indicator to measure the relative importance of common factors. By transforming formula 2, we get the following results:

$$
\operatorname{Var}\left(x_{i}\right)=\alpha_{i 1}^{2} \operatorname{Var}\left(f_{1}\right)+\alpha_{i 2}^{2} \operatorname{Var}\left(f_{2}\right)+\cdots+\alpha_{i k}^{2} \operatorname{Var}\left(f_{k}\right)+\operatorname{Var}\left(\beta_{i}\right)=\sum_{j=1}^{k} \mathrm{~g}_{i j}^{2}+\sum_{i=1}^{p} \beta_{i}^{2}
$$

The larger $\mathrm{g}_{j}^{2}$, the greater contribution of the common factor $\mathrm{F}(\mathrm{fl}, \mathrm{f} 2, \mathrm{f} 3, \ldots \ldots$, fk) to $X(x 1, x 2, x 3, \ldots \ldots, x p)$, or the greater the influence and effect of $X(x 1, x 2, x 3$, , xp).If all $\mathrm{g}_{j}^{2}(\mathrm{j}=1,2, \ldots, \mathrm{k})$ of the factor load matrix A are calculated, sort them by size, we can extract the most influential public factors. Finally, three common factors with characteristic root greater than 1 are proposed, namely, three dimensions, with nine items in total, which are learning for application ability (learning ability, knowledge application ability, creativity ability), emergency cooperation ability (adaptability, team cooperation ability, interpersonal communication ability), and 
organizational practice ability (organizational leadership ability, practical ability, and organizational coordination ability). The factor loads of 9 items are all above 0.4 .

\section{Teaching Example and Teaching Effect}

\subsection{Teaching example}

Based on the background of innovative talents training, this study constructs the three track teaching model on the basis of input variables, intervention process variables and output variables in the "school learning model", The input variables are named "the quantity of existing knowledge", "the quality of problems" and "the performance of tutors"; The intervention process variable is the learning process variable of PBL - "tutor group effectiveness"; The output variables include cognitive results and emotional outcomes, namely, "students' learning achievement" and "interest in subject content" determined by students' "autonomous learning time". Among them, the "learning time" changes from intervention process variable to output variable. The specific implementation model is shown in Figure 6, and the implementation steps are shown in Table 1.

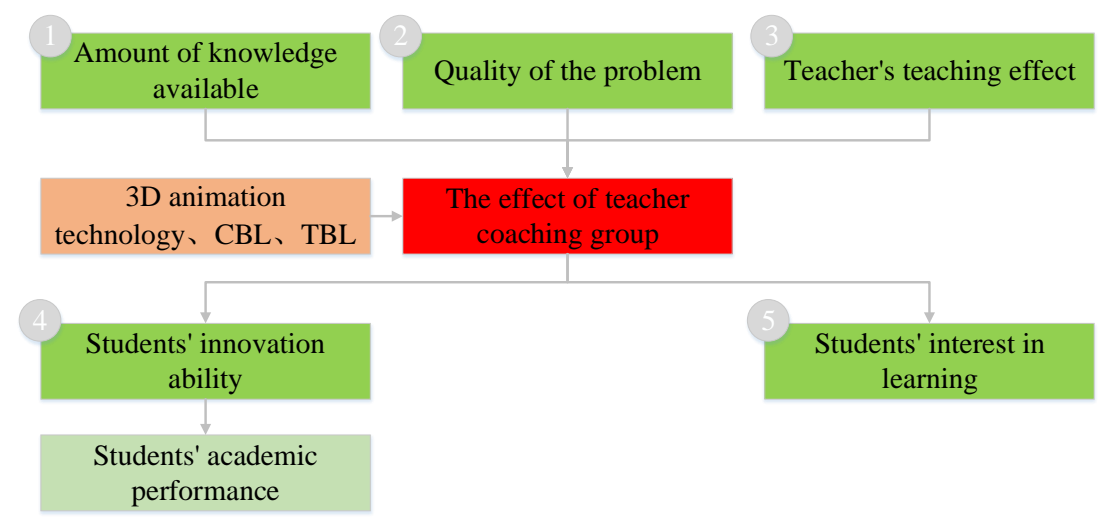

Fig. 6. Implementation model of three track teaching method based on innovation theory 
Table 1. Implementation steps of three track teaching mode of sports anatomy

\begin{tabular}{|c|c|c|}
\hline Step & Content & Skill \\
\hline 1 & Describe the problem and clarify the unknown terms and concepts & \multirow{3}{*}{$\begin{array}{l}\text { Activation of existing } \\
\text { knowledge; cooperation; } \\
\text { information construction or } \\
\text { reconstruction; organizational } \\
\text { information; internal } \\
\text { motivation } \\
\end{array}$} \\
\hline 2 & Define the problem and list the phenomena and events to be explained & \\
\hline 3 & $\begin{array}{l}\text { Analyze the problem: the first step is brainstorming. Encourage } \\
\text { students to rely on existing knowledge and common sense to come up } \\
\text { with as many explanations as possible }\end{array}$ & \\
\hline 4 & $\begin{array}{l}\text { Analysis of the problem: the second step, discussion. Judge the } \\
\text { numerous explanations proposed and determine the one that best } \\
\text { reflects the principle or mechanism contained in the phenomenon or } \\
\text { event }\end{array}$ & \multirow{4}{*}{$\begin{array}{l}\text { Construction and } \\
\text { reconstruction; application; } \\
\text { problem solving }\end{array}$} \\
\hline 5 & $\begin{array}{l}\text { Determine the missing content of existing knowledge, and then } \\
\text { determine the goal and content of autonomous learning }\end{array}$ & \\
\hline 6 & $\begin{array}{l}\text { Through self-learning to obtain the content needed to solve the } \\
\text { problem }\end{array}$ & \\
\hline 7 & $\begin{array}{l}\text { In the tutor group, share and synthesize their own gains to form a final } \\
\text { and reasonable explanation of the phenomenon or event. Test whether } \\
\text { the knowledge and skills acquired by students are sufficient to explain } \\
\text { the phenomenon or solve the problem }\end{array}$ & \\
\hline
\end{tabular}

It can be seen from table 3 that if the three-track teaching method wants to achieve the expected training objectives, the first thing to do is to carefully design questions. The problems here are not simple general questions. Students can find the answers by reading books, but design complex problems. The so-called complex problems refer to those involving more knowledge points, and the answers cannot be easily found. Moreover, the answers are not fixed but open. Students need to use a variety of tools to find out, and even to investigate and interview in order to obtain answers. In this study, students will be informed one or two weeks in advance about the design questions of each teaching unit. The students will learn by themselves in groups and work together to find the answers. The students form teams by themselves. The teachers encourage and urge them to actively communicate and discuss. Each member of the team is assigned tasks by the person in charge. The performance of each student in the team not only affects himself, but also affects his teammates, which is conducive to cultivating the team work spirit of students. After checking all the students' homework, the teacher should prepare the important and difficult points in class according to the students' self-study. Reasonable use of case teaching, for example, when focusing on the characteristics of the knee joint, the common knee joint injury in sports can be taken as a case, and the structure of the knee joint can be directly displayed through 3D sports anatomy software to stimulate students' interest and innovation ability. After the above work is completed, the teacher will have a summary and evaluation link, which will be arranged in the class we-chat group after class. Students' self-evaluation and peer-to-peer evaluation are required to give the score and the reason for the score. Finally, the teacher will give the final score based on the self-evaluation, mutual evaluation, oral report and written manuscript, which accounts for $30 \%$ of the final score of the course. 


\subsection{Teaching effect}

From March to July in 2020, two classes of freshmen in physical education major of a university in Hunan province were selected and randomly divided into experimental class and control class. The experimental group of 52 people, using the three-track teaching mode for teaching, at the same time integrating innovative theory, applied 3D anatomy software in the teaching process. In the control group of 50 students, adopting the traditional teaching mode based on teacher teaching. Before the experiment, there were no significant differences in educational background, gender, age and academic performance between the two groups $(\mathrm{P}>0.05)$.

The results showed that the average score of the experimental group was 83.00, as showed in Table 2. And that of the control group was 73.30. The comprehensive assessment score of the experimental group was significantly higher than that of the control group $(\mathrm{P}<0.01)$. At the same time, the excellent and good rate of the experimental group was significantly higher than that of the control group, indicating that the three-track teaching mode has a great role in promoting students' learning. See Table 2 for details.

Table 2. Comparative analysis of comprehensive examination results of two groups

\begin{tabular}{|l|c|c|c|c|c|c|}
\hline \multicolumn{1}{|c|}{ Group } & $\begin{array}{c}\text { Comprehensive examination } \\
\text { results }\end{array}$ & Excellent & Good & Medium & Pass & Fail \\
\hline Experimental group(n=52) & 83.0 & 18 & 17 & 13 & 2 & 2 \\
\hline Control group(n=50) & 73.3 & 4 & 17 & 17 & 8 & 4 \\
\hline
\end{tabular}

In conclusion, the three-track teaching method based on innovation theory can effectively improve students' academic performance and improve their learning satisfaction. The main reasons are as follows: firstly, based on the sports practice, the three-track teaching method in this study timely applies the cases familiar to the students to conduct knowledge introduction before class, and constructs a teaching situation of sports practice, which is consistent with the characteristics of sports major, so as to improve the teaching effect and improve the students' academic performance. At the same time, in the teaching of abstract anatomy theory to students, help students to carry out team cooperation, to team knowledge competition, or to complete the task to stimulate students' interest, which not only improve students' innovation ability, but also improve students' interest in learning, learn how to apply theoretical knowledge to sports practice, cultivate students' practical problem-solving ability. For example, encouraging students to make and report PPT independently around the knowledge points of cases and learning tasks before class, it can also help to improve students' knowledge level. More importantly, this teaching method uses 3D anatomy teaching software, which can simulate anatomical operation and realize three-dimensional organ structure to the maximum extent, so that students can learn knowledge in the software operation. The software built with 3D virtual technology can also carry out exploratory operation on the model from any angle in the realistic scene, so that students can learn with a relaxed and positive attitude, and can learn knowledge unconsciously and improve their academic performance. 


\section{Conclusion}

With the theoretical support of innovative talent training, this study constructed a three-track teaching model based on 3D anatomy software, and this teaching mode is applied to the course practice of sports anatomy. The results show that the organic combination of multimedia technology and traditional teaching is a teaching method to improve the teaching effect of anatomy, which is applied in the course of sports anatomy. It is very necessary and feasible. At the same time, the following conclusions are drawn in the teaching practice:

1. The teaching method of this teaching mode is vivid and easy to understand. In the teaching process, teachers can better listen to students' opinions, collect more realistic and diversified.There are also problems (cases) analysis that can cultivate students' innovative ability.

2. In the course, teachers should set up interesting and difficult teaching tasks, coordinate the distribution of course scores, create a better teaching atmosphere, increase students' awareness of the three track teaching method, and further improve the teaching effect of teachers.

3. In the process of implementing this teaching method, the teacher, as a guide, needs to coordinate the learning ability gap between students, support the students with poor learning ability to quickly integrate into the team learning atmosphere, and make the poor students integrate into the new teaching mode well.

4. In brief, the exploration of the three track teaching method based on innovative theory in the course of sports anatomy is successful, but this research needs to be further expanded in the future, hoping that the teaching method can be better implemented, avoid the disadvantages of the traditional mode, so as to promote the comprehensive quality of students.

\section{Acknowledgement}

A Project Supported by Ordinary Colleges Teaching Reform and Research Project of Hunan Province (HNJG-2020-1112).

\section{$7 \quad$ References}

[1] Park, C.W., Kim, D.G., Cho, S., \& Han, H.J. Adoption of multimedia technology for learning and gender difference. Computers in Human Behavior, 2019, vol. 92, pp. 288296. https://doi.org/10.1016/j.chb.2018.11.029

[2] Salajan, F.D., \& Mount, G.J. Leveraging the power of web 2.0 tools: a wiki platform as a multimedia teaching and learning environment in dental education. Journal of Dental Education, 2012, vol. 76(4), pp. 427-436. https://doi.org/10.1002/j.0022-0337.2012.76.4.tb $\underline{05274 . X}$

[3] Ren, Y.J., Jiang, X., \& Tang, S.Y. 3dbody software experimental platform for course of sports anatomy. International Journal of Emerging Technologies in Learning, 2017, vol. 12(9), pp. 4-16. https://doi.org/10.3991/ijet.v12i09.7482 
[4] Ren, Y.J, \& Jiang, X. A mind map teaching mode for sports anatomy based on 3dbody. International Journal of Emerging Technologies in Learning, 2019, vol. 14(10), pp. 4-17. https://doi.org/10.3991/ijet.v14i10.10776

[5] Adamovillani, N., Doublestein, J., \& Martin, Z. Sign Language for K-8 Mathematics by 3D Interactive Animation. Journal of Educational Technology Systems, 2005, vol. 33(3), pp. 241-257. https://doi.org/10.2190/kub1-6m7x-nhy5-3bwg

[6] Korakakis, G., Boudouvis, A., Palyvos, J., \& Pavlatou, E.A. The impact of 3d visualization types in instructional multimedia applications for teaching science. Procedia Social \& Behavioral Sciences, 2012, vol. 31(30), pp. 145-149. https://doi.org/10.1016/j.sbspro.2011. $\underline{12.032}$

[7] Hoyek, N., Collet, C., Rienzo, F. D., De Almeida, M., \& Guillot, A. Effectiveness of threedimensional digital animation in teaching human anatomy in an authentic classroom context. Anatomical Sciences Education, 2014, vol. 7(6), pp. 430-437. https://doi.org/10. $1002 /$ ase. 1446

[8] Zhou, Y., Xu, Z.K. Digital 3D interactive model making technology for human anatomy structure. China Medical Education Technology, 2016, vol. 30(4), pp. 405-407.

[9] Assadi, S.N. Problem- Based Learning for Determination of Fitness for Work and Return to Work. Research and Development in Medical Education, 2016, vol. 5(2), pp. 85-88. https://doi.org/10.15171/rdme.2016.017

[10] Nicklen, P., Keating, J. L., Paynter, S., Storr, M., \& Maloney, S. Remote-online case-based learning: A comparison of remote-online and face-to-face, case-based learning - a randomized controlled trial. Education and Health, 2016, vol. 29(3), pp. 195-202. https:// doi.org/10.2196/mededu.5348

[11] Michaelsen, L. K., \& Sweet, M. The Essential Elements of Team-Based Learning. New Directions for Teaching and Learning, 2008, vol. 116, pp. 7-27. https://doi.org/10.1002/ $\underline{\mathrm{t} l .330}$

[12] Sendag, S., \& Duran, M. Comparing preservice teachers' perceptions of online problembased learning and online instructor-led learning. Procedia - Social and Behavioral Sciences, 2012, vol. 31, pp. 212-217. https://doi.org/10.1016/j.sbspro.2011.12.044

[13] Hrynchak, P. K., \& Batty, H. The educational theory basis of team-based learning. Medical Teacher, 2012, vol. 34(10), pp. 796-801. https://doi.org/10.3109/0142159x.2012.687120

[14] Cai, T., Zhang, C.L. Try and thinking of "three track teaching mode" in orthopedics Teaching. China Higher Medical Education, 2017, vol. 252(12), pp. 73-74.

[15] Li, T.F., Wang, J., Wang, S., Yao, Y. Practice and exploration of TBL teaching method in cardiovascular internal medicine teaching. China Higher Medical Education, 2014, vol. 26(5), pp. 109-110.

\section{Authors}

Yujia Ren is an associate professor in the Physical Education Institute, Hunan First Normal University, Changsha 410205, Hunan, China (renyujia@163.com).

Rong Tang is a Lecturer in the Xiangtan Medicine \& Health Vocational College, Xiangtan 411104, China (940954767@qq.com).

Xia Jiang is an associate chief physician in the Wuhan Sports University, Wuhan 430079, China (274541977@qq.com).

Article submitted 2020-09-30. Resubmitted 2020-10-27. Final acceptance 2020-10-29. Final version published as submitted by the authors. 